\title{
OPTIMISATION OF REACTION PARAMETERS FOR THE SYNTHESIS OF SOLKETAL LEVULINATE AS POTENTIAL BIODIESEL ADDITIVE
} NMD NIK SITI MARIAM ${ }^{1 *}$; SENG SOI HOONG ${ }^{1}$; MOHD ZAN ARNIZA ${ }^{1}$; SRIHANUM ADNAN ${ }^{1}$; TUAN
NOOR MAZNEE TUAN ISMAIL'; SHOOT KIAN YEONG ${ }^{1}$ and MUHAMMAD RAHIMI YUSOP ${ }^{2}$

\begin{abstract}
Glycerol is a major by-product of biodiesel production and finding new uses for glycerol is crucial to ensure the sustainability and continuance of the biodiesel industry. Thus, the transformation of glycerol into ketal compounds that have potential as additive to improve biodiesel properties, could be an option to provide an outlet for increasing glycerol stock. This study aims to optimise the transesterification reaction to afford solketal levulinate ester (SoLE) in highest yield by reacting solketal with methyl levulinate $(M L)$. The reaction parameters varied are type of base catalyst, catalyst concentration, reaction temperature, reaction time and reactants molar ratio. Under optimised reaction conditions: $1.5 \%$ sodium carbonate $\left(\mathrm{Na}_{2} \mathrm{CO}_{3}\right)$ catalyst loading, reaction temperature of $140^{\circ} \mathrm{C}$, reaction time of $4 \mathrm{hr}$ and molar ratio of $3: 1$ (solketal:ML), as high as $74.5 \%$ yield and $95 \%$ purity of SoLE was obtained.
\end{abstract}

\section{Keywords: glycerol, levulinate, lignocellulosic biomass, palm oil, solketal ester.}

Received: 26 April 2021; Accepted: 10 October 2021; Published online: 21 December 2021.

\section{INTRODUCTION}

Glycerol (propane-1,2,3-triol) is the simplest alcohol with three hydroxyl $(\mathrm{OH})$ group. It is also known as glycerin. Glycerol demonstrates versatile uses in numerous fields such as in food improver, pharmaceutical product, polymer industries, fuel and diesel additive (Anitha et al., 2016). Glycerol (Gly) is made as a by-product commonly from biodiesel production where approximately $10 \%$ by volume for every tonne of biodiesel (Karinen and Krause, 2006).

The global growth of biodiesel production over the last decade had caused surplus of glycerol in the marketplace which resulted in decline of

\footnotetext{
Malaysian Palm Oil Board,

6 Persiaran Institusi, Bandar Baru Bangi,

43000 Kajang, Selangor, Malaysia.

2 School of Chemical Sciences and Food Technology, Faculty of Science and Technology,

Universiti Kebangsaan Malaysia,

43600 Bangi, Selangor, Malaysia.

* Corresponding author e-mail: nsmariam@mpob.gov.my
}

glycerol price, hence threaten the economic viability of biodiesel plants. Other than that, glycerol also comes from oleochemical plant. There are currently 19 oleochemical plants operating in Malaysia, which exported approximately 3.28 million tonnes of oleochemicals in 2019 (Parveez et al., 2020). Therefore, new uses of glycerol are needed if the present and future glycerol stock is to be managed (Lapuerta et al., 2015). Glycerol ketals and acetals are among interesting compounds to be explored, as they have been demonstrated as potential additive in the formulation of gasoline, diesel and biodiesel fuels to improve fuel properties (Nanda et al., 2016). Solketal improves cold flow, ignition properties and cetane number of fuels (Kumar et al., 2021), while the use of glycerol acetals in diesel fuels (biodiesel) reduces the viscosity, pour point and particles emission (Torres et al., 2012). Solketal is derived from condensation of glycerol and acetone in the presence of acid catalysts (Deutsch et al., 2007; Li et al., 2012; Suriyaprapadilok and Kitiyanan, 2011). Solketal can be used as a fuel additive to reduce the particulate emission and to improve the cold flow 
properties of liquid transportation fuels (Pariente et al., 2009). It helps to reduce the gum formation, improves the oxidation stability, and enhances the octane number when added to gasoline (Mota et al., 2010). Maksimov et al. (2011) reported its use as a versatile solvent and a plasticiser in the polymer industry and a solubilising and suspending agent in pharmaceutical preparations.

The free $-\mathrm{OH}$ in solketal can also be further reacted to give solketal fatty esters (SFE) via basecatalysed transesterification with fatty acid methyl esters (FAMEs) (Trifoi et al., 2016). Solketal ester and their cyclic group family correspondingly have been reported as an useful fuel additive for enhancing octane number of gasoline (Lozano et al., 2016). Other than that, biodiesels formulations based on mixtures of FAME and fatty acid glycerol formal esters (FAGE) have been described as very efficient for diesel engines. Biodiesel blends up to $20 \%$ volume fraction of FAGE, exhibited an excellent suitability as liquid fuel (e.g. viscosity, cetane number, adiabatic flame temperature, etc.), as it was demonstrated by testing in an automotive engine (Lozano et al., 2016; Nanda et al., 2016; Perosa et al., 2016).

The oil palm industry generates a large quantity of oil palm biomass on yearly basis and it was estimated that in year 2016, the Malaysian palm oil industry generated 80 million tonnes of oil palm biomass (Din et al., 2019). Levulinic acid (LA) is a value-added chemical that can be obtained from lignocellulosic biomass. LA and its derivatives have been used as building blocks for the preparation of new compounds such as levulinate esters, $\alpha$-valerolactone, acrylic acid and 1,4-pentanediol (Bozell et al., 2000; Girisuta and Heeres, 2017; Rackemann and Doherty, 2011).

The most highlighted LA derivatives are their esters (Adeleye et al., 2019; Castro and Fernandes, 2021; Din et al., 2019; Tiong et al., 2019). The properties of levulinate esters such as methyl and ethyl levulinate (EL) have been investigated for application as gasoline and diesel additives (Liang et al., 2020; Unlu et al., 2018; Vázquez-Castillo et al., 2019; Xu et al., 2020). EL is considered as a bio-based cold flow improver for biodiesel, as it has shown to reduce cloud point of biodiesel and the resultant mixture of biodiesel and EL showed better cold flow properties. It also has additional excellent properties such as clean combustion and low toxicity for fuel additive (Joshi et al., 2011).

High-efficiency process parameters is an inevitable topic of discussion in synthesis process for sustainable synthetic chemistry (Castro and Fernandes, 2021). The synthesis of levulinate ester using LA and short chain alcohol is reported to be conducted mostly via esterification reaction employing different mineral acid catalysts, such as sulphuric acid $\left(\mathrm{H}_{2} \mathrm{SO}_{4}\right)$, hydrochloric acid $(\mathrm{HCl})$ and phosphoric acid $\left(\mathrm{H}_{3} \mathrm{PO}_{4}\right)$ (Bart et al., 1994;
Liu et al., 2006; Pileidis et al., 2014), and various solid acids, such as sulphonic acid functionalised materials (Oliveira and Teixeira da Silva, 2014; Song et al., 2015). However, we found that the esterification of solketal with LA in the presence of acid catalyst gave unsatisfactory yield of solketal levulinate ester (SoLE). This is due to possibility of hydrolysis of solketal under acidic condition forming undesirable side product. This is in agreement with the work reported by Pouilloux et al. (2000), where they reported utilisation of acid catalyst favours side reactions such as degradation of the fatty acid (oxidation, dimerisation) or from the glycerol (polymerisation, dehydration into acrolein, oxidation). Hence, we adopt basedcatalysed transesterification of solketal with methyl levulinate $(\mathrm{ML})$, where base catalyst and ML were utilised instead of acid catalyst and LA. Thus, this article reported the further optimisation of reaction parameters such as type of catalyst, effect of reaction duration, temperature and molar ratio of solketal / ML to attain maximum yield of solketal levulinate. To the best of authors' knowledge, no literature reported on the optimisation of transesterification reaction of solketal and levulinic ester for the synthesis of solketal levulinate, which potentially can be used as fuel additive in biodiesel.

\section{MATERIALS AND METHODS}

\section{Materials}

Refined solketal (99.8\% purity) and ML (98\%) were obtained from Sigma Aldrich, USA. Sodium carbonate $\left(\mathrm{Na}_{2} \mathrm{CO}_{3}\right)$ and potassium carbonate $\left(\mathrm{K}_{2} \mathrm{CO}_{3}\right)$ were obtained from Systerm, Malaysia. Sodium hydroxide $(\mathrm{NaOH})$ was obtained from R\&M Chemicals, Malaysia, and potassium hydroxide $(\mathrm{KOH})$ was obtained from Chemiz, Malaysia. Magnesium oxide $(\mathrm{MgO})$ and sodium methoxide (30\% in $\mathrm{MeOH}, \mathrm{NaOMe}$ ) both were obtained from Sigma Aldrich, USA. All the reagents were used without further purification.

\section{Methods}

General procedure for the synthesis of solketal levulinate (SoLE). Reactions were carried out in a $50 \mathrm{ml}$ one-neck round bottom flask equipped with a magnetic stirrer. A condenser was attached to the round bottom flask and connected to a vacuum pump to facilitate removal of methanol from the reaction system. Desired amount of solketal, ML and $\mathrm{Na}_{2} \mathrm{CO}_{3}$ (catalyst) were placed in the flask and heated to the desired temperature. An oil bath equipped with a thermometer was used to monitor the reaction temperature. Figure 1 is the diagram of the reaction setup. The amount of reagents was 
calculated according to the desired mole ratio. The reaction progress was monitored via thin-layer chromatography analysis. After the reaction was completed, the crude mixture was washed with distilled water to remove the basic catalyst, followed by addition of diethyl ether to extract SoLE. The organic layer was concentrated under vacuum using roto-evaporator. Thereafter, the product was evaluated using gas chromatography (GC), Proton $\left({ }^{1} \mathrm{H}\right)$ and carbon $\left({ }^{13} \mathrm{C}\right)$ nuclear magnetic resonance (NMR) spectroscopy and Fourier transform infrared (FTIR) spectroscopy.

\section{Analysis and Characterisation of SoLE}

FTIR. A convenient analytical method for determining the functional groups of the SoLE was conducted using Perkin Elmer Spectrum 100 FTIR Spectrometer equipment with attenuated total reflectance (ATR). Samples were scanned on ATR top plate between 4000 to $650 \mathrm{~cm}^{-1}$ wave number with 8 scans per sample at $4 \mathrm{~cm}^{-1}$ resolution.

GC analysis. Quantitative analysis of the reaction mixture was conducted using GC. The GC (Agilent System 6890N Network GC System) was equipped with a ZB-5HT INFERNO (30 m x $250 \mu \mathrm{m}$ x $0.2 \mu \mathrm{m})$ capillary column and flame ionisation detector. The following temperature programming was used: oven temperature, $80^{\circ} \mathrm{C}$; initial temperature, $80^{\circ} \mathrm{C}$; heating rate at $10^{\circ} \mathrm{C} \mathrm{min}^{-1}$; final temperature, $315^{\circ} \mathrm{C}$; injector temperature, $300^{\circ} \mathrm{C}$; detector temperature,

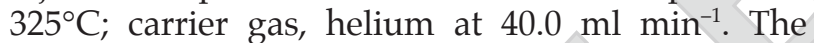
composition of products was determined according to the percent area under the respective peak in the GC chromatogram.
${ }^{1} \mathrm{H}$ and ${ }^{13} \mathrm{C}$ NMR analysis. ${ }^{1} \mathrm{H}$ and ${ }^{13} \mathrm{C}$ NMR spectroscopy were recorded on JOEL JNM-ECZ600R at $600 \mathrm{MHz}$ and $150 \mathrm{MHz}$, respectively at $298 \mathrm{~K}$ with approximately $10 \% \mathrm{w} / \mathrm{v}$ solutions in deuterated NMR solvents. Chemical shifts were quoted in ppm relative to internal standard tetramethylsilane (TMS) and reference to the residual solvent. All coupling constants were quoted in hertz $(\mathrm{Hz})$.

\section{RESULTS AND DISCUSSION}

\section{Effect of Reaction Parameters on the Yield of SoLE}

Influence of different types of catalysts. SFE can be prepared by the catalytic esterification of fatty acids with solketal (Sankaranarayanan et al., 2017). Acidic homogeneous catalysts, such as $\mathrm{H}_{2} \mathrm{SO}_{4}, \mathrm{HCl}$, hydrogen fluoride $(\mathrm{HF})$ and $p$-toluenesulphonic acid, can be applied for this process. Although the homogeneously acid catalysed processes give high conversion of solketal, they also generates a large amount of waste from the neutralisation and separation of the acidic catalyst (Ilgen et al., 2017). Conversely, the use of base catalysts (Figure 1) has advantages that can overcome the drawbacks of acid catalyst. Therefore, in this study, the influences of base catalyst on transesterification of solketal with ML were studied. In this work, base catalysts were tested instead of the acidic catalyst in order to prevent several side reactions associated with acid catalyst such as cleavage of the acetonide of solketal. The following reaction parameters were fixed while several base catalysts were evaluated: mole ratio (ML:solketal) - 1:1.5; reaction temperature of $140^{\circ} \mathrm{C}$; reaction duration of $6 \mathrm{hr}$.

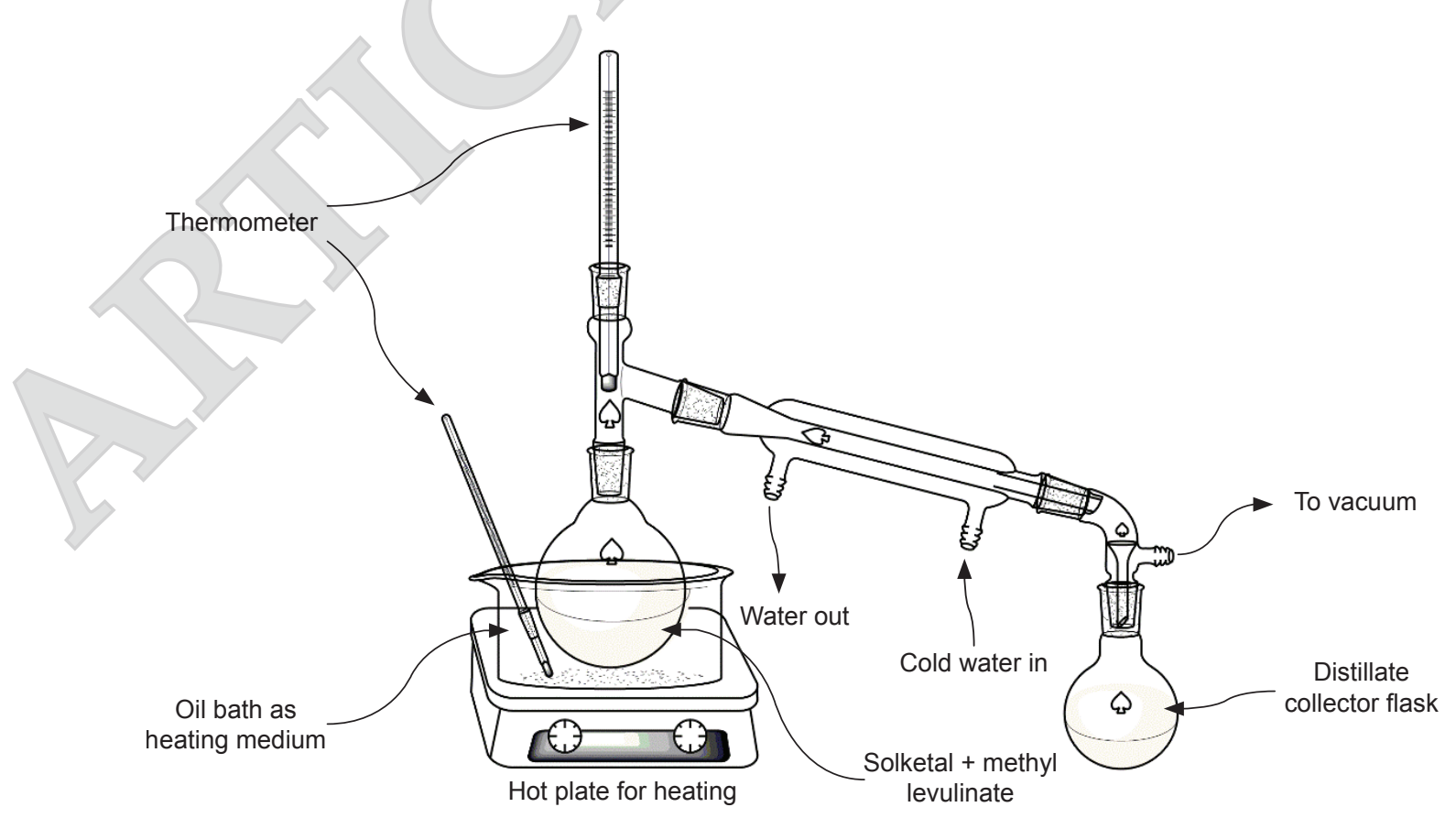

Figure 1. Reaction diagram of transesterification reaction of solketal with methyl levulinate $(M L)$. 
Application of base catalyst in transesterification reaction provides faster rate, nearly 4000 times faster than that catalysed by the same amount of an acid catalyst (Fukuda et al., 2001). In this reaction, six homogeneous base catalysts were tested: $\mathrm{Na}_{2} \mathrm{CO}_{3}, \mathrm{~K}_{2} \mathrm{CO}_{3}, \mathrm{NaOH}, \mathrm{KOH}, \mathrm{MgO}$ and $\mathrm{NaOMe}$. The effect of different catalysts on the yield of SoLE is illustrated in Figure 2.

$\mathrm{K}_{2} \mathrm{CO}_{3}$ exhibited the best catalytic activity affording the highest yield of SoLE (57.29\%), followed by $\mathrm{Na}_{2} \mathrm{CO}_{3}(49.88 \%)$ (Figure 3). On the other hand, both hydroxide and oxide bases gave low yield of SoLE between 3.8\% and $17.36 \%$, respectively. $\mathrm{NaOMe}$ was notable to be the paramount catalyst in transesterification of vegetable oil with methanol to produce methyl ester as biodiesel (Atadashi et al., 2013). However, in this reaction, $\mathrm{NaOMe}$ generated only 29\% yield of SoLE as shown in Figure 3. Therefore, we selected the two carbonate bases, $\mathrm{K}_{2} \mathrm{CO}_{3}$ and $\mathrm{Na}_{2} \mathrm{CO}_{3}$ as the catalysts for further optimisation.

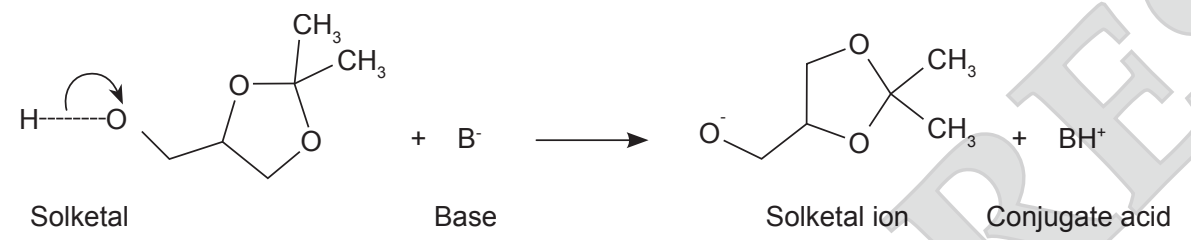

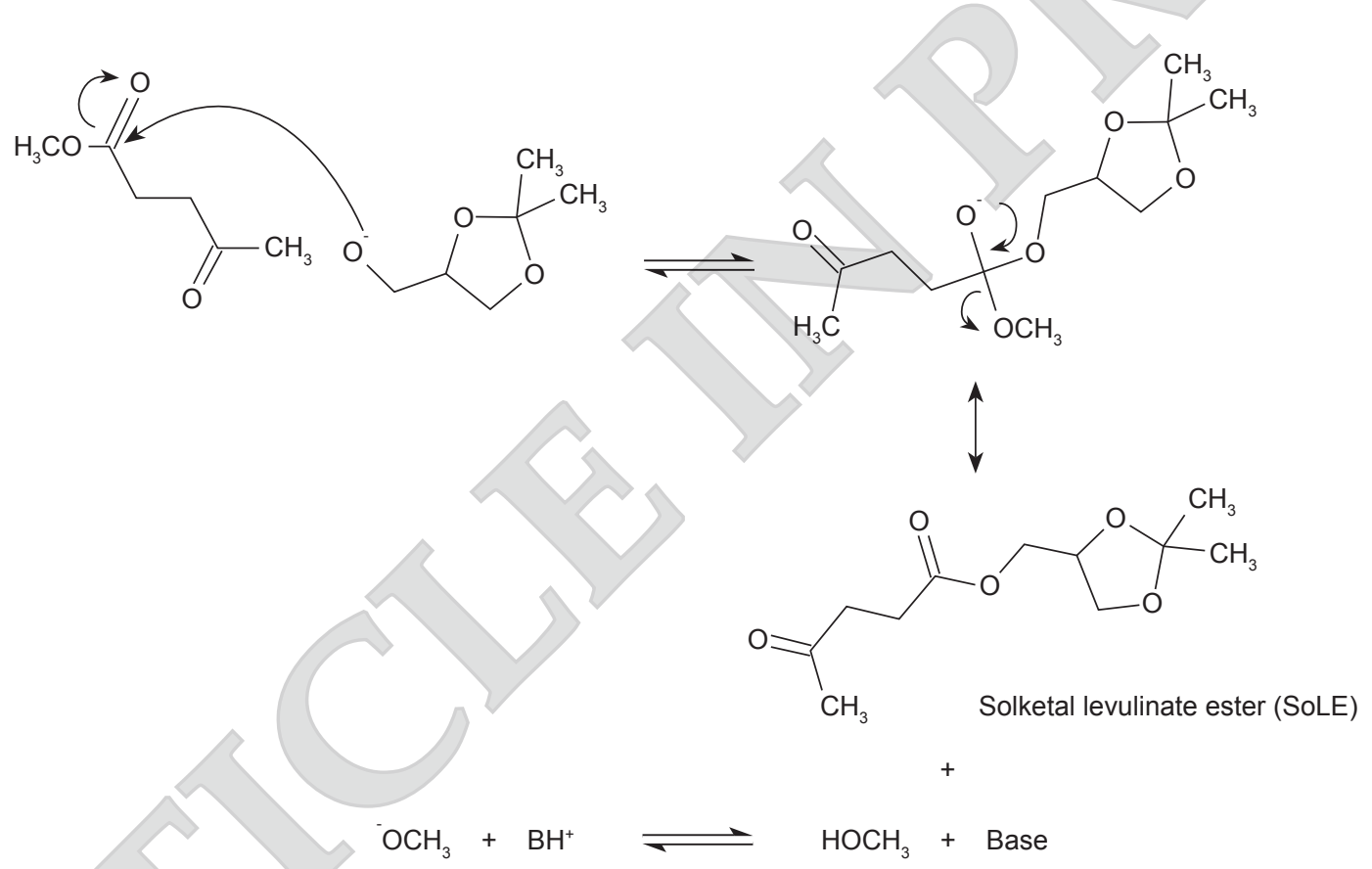

Figure 2. Reaction mechanism of based-catalysed transesterification reaction of solketal with methyl levulinate (ML).

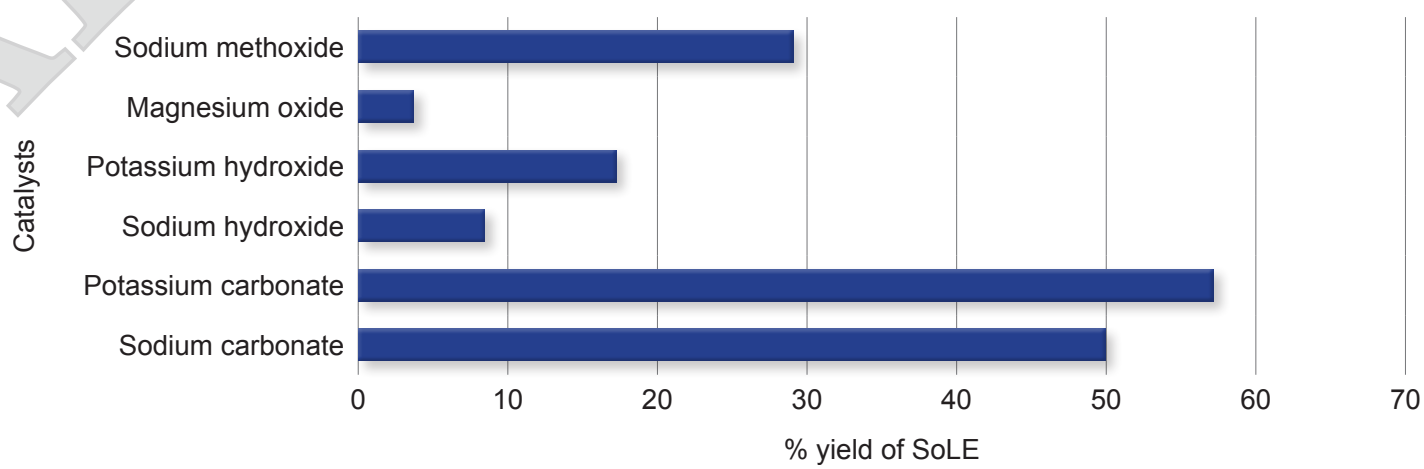

Figure 3. Effect of different type of base catalyst on the yield of SoLE. 


\section{Influence of Reaction Time on Yield of SoLE}

We then investigated the effect of reaction time on the yield of SoLE, while keeping the following reaction parameters constant throughout this set of the experiments and two types of catalysts were used: molar ratio of ML:solketal $=1: 3$; reaction temperature of $140^{\circ} \mathrm{C} ; 1 \%$ catalyst loading of $\mathrm{K}_{2} \mathrm{CO}_{3}$ and $\mathrm{Na}_{2} \mathrm{CO}_{3}$.

The reaction between solketal and $\mathrm{ML}$ was terminated at predetermined reaction duration, which were $2,3,4,6$ and $8 \mathrm{hr}$. The reaction mixture was stirred vigorously in order to achieve perfect contact between the reagents and the catalyst through the process (Ramadhas et al., 2005). The effect of reaction time on the yield of SoLE is shown in Figure 4. The results essentially indicated that the yield of SoLE increased with longer reaction time. The result clearly showed that the maximum yield of SoLE was obtained after $4 \mathrm{hr}$ of reaction for $\mathrm{Na}_{2} \mathrm{CO}_{3}$-catalysed reaction and $6 \mathrm{hr}$ of reaction for $\mathrm{K}_{2} \mathrm{CO}_{3}$-catalysed reaction. Reaction time of $4 \mathrm{hr}$ is more favourable due to time and cost effective of the reaction. Thus, $\mathrm{Na}_{2} \mathrm{CO}_{3}$ and reaction time of $4 \mathrm{hr}$ were selected as the catalyst and optimum reaction time, respectively for the transesterification process. The selected catalyst is in agreement with a study reported by $\mathrm{Yu}$ et al. (2003) that employed $\mathrm{Na}_{2} \mathrm{CO}_{3}$ as the catalyst in transesterification of solketal with fatty acid such as stearic acid.

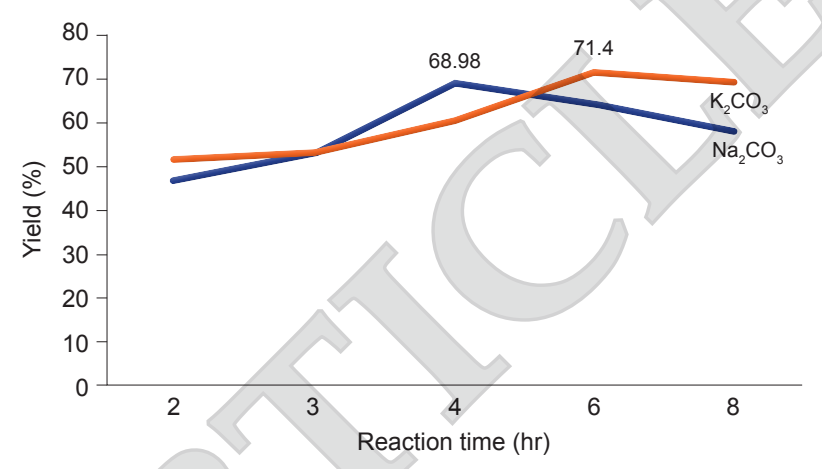

Figure 4. The effect of reaction time on the yield of SoLE.

\section{Influence of Catalyst Loading}

It is well documented that esterification/ transesterification reactions require acid/base catalysts and the strength of the acid/base used is an important factor affecting the kinetics of the reaction (Rastegari and Ghaziaskar, 2015). The amount of catalyst in a reaction system will greatly influence the effectiveness of the catalyst. Therefore, in order to study the effect of catalyst loading on the yield of SoLE, the following reaction parameters were fixed as follow: molar ratio of ML:solketal $=1: 3$; reaction temperature of $140^{\circ} \mathrm{C}$; reaction time of $4 \mathrm{hr}$.
The catalyst loading was varied from $1 \%$ to $3 \%$. The change of yield of SoLE in respect to catalyst concentration is shown in Figure 5. The result showed that the yield of SoLE increased gradually with higher catalyst loading up to $1.5 \%$ and slightly decreased at catalyst loading higher than $1.5 \%$. The highest yield of SoLE obtained with $1.5 \%$ catalyst was $74.6 \%$. Other than that, excess addition of catalyst will lead to SoLE with darker colour. In the next stage of study, $\mathrm{Na}_{2} \mathrm{CO}_{3}$ loading amount of $1.5 \%$ will be used in subsequent sections of the study.

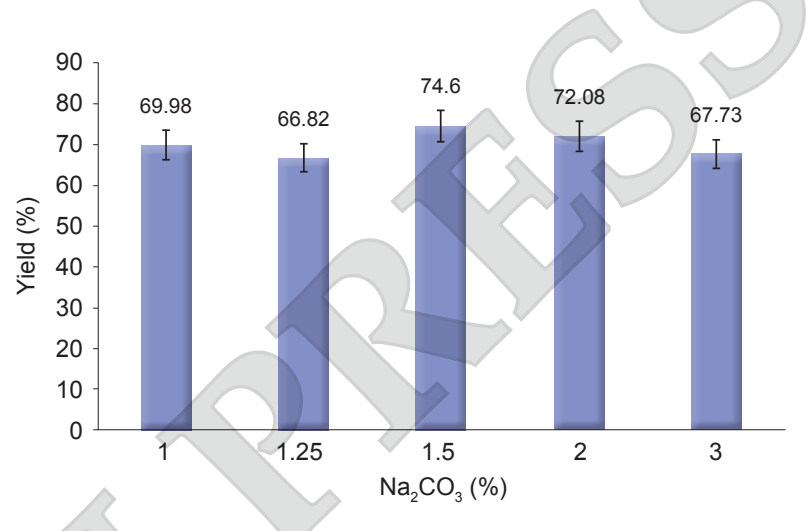

Figure 5. Effect of catalyst loading on the yield of solketal.

\section{Influence of Molar Ratio of ML to Solketal}

The mole ratio of ML to solketal is one of the most important variables affecting the yield of SoLE. Stoichiometrically, one mole of solketal is required per mole of ML, but in practice an excess of alcohol is employed in order to displace the equilibrium to produce more ester. The molar ratio of ML to solketal was varied from 1:2 to 1:4.5, while the other reaction parameters were kept constant as follow: $\mathrm{Na}_{2} \mathrm{CO}_{3}$ $(1.5 \%)$; reaction temperature of $140^{\circ} \mathrm{C}$; reaction duration of $4 \mathrm{hr}$. Figure 6 shows the yield of SoLE against molar ratio of ML to solketal. Molar ratio of 1:3 (ML:solketal) was the optimum mole ratio that gave best yield of SoLE of $74.6 \%$. When the amount of solketal was increased above or reduced below the optimal amount, the reaction condition did not increase the yield of SoLE. Hence, molar ratio of 1:3 will be used for the next section of the study.

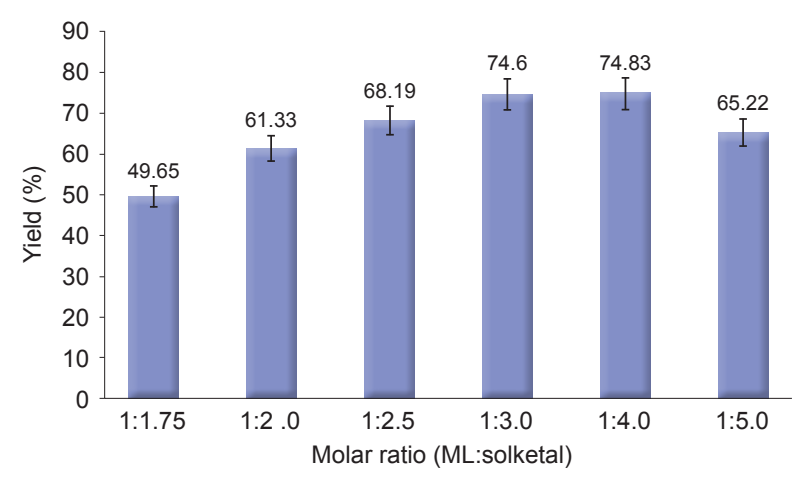

Figure 6. Effect of molar ratio (ML:solketal) on the yield of SoLE. 


\section{Effects of Reaction Temperature}

Temperature is a significant factor that affects the transesterification reaction, where relatively it will influence the yield of product. To determine the effect of reaction temperature on the yield of SoLE, the reaction temperature was varied from $80^{\circ} \mathrm{C}$ to $160^{\circ} \mathrm{C}$, while the other reaction parameters were kept constant as follow: molar ratio of ML:solketal $=1: 3 ; \mathrm{Na}_{2} \mathrm{CO}_{3}(1.5 \%)$; reaction time of $4 \mathrm{hr}$. Figure 7 shows the yield of SoLE against reaction temperature. The figure shows that the yield of SoLE gradually increased until the reaction temperature of $140^{\circ} \mathrm{C}$, giving $74.6 \%$ yield. As the reaction temperature continue to increase, the yield of SoLE slightly decreased. According to results, reaction temperature of $140^{\circ} \mathrm{C}$ gave the highest yield of SoLE and it was regarded to be the optimum value.

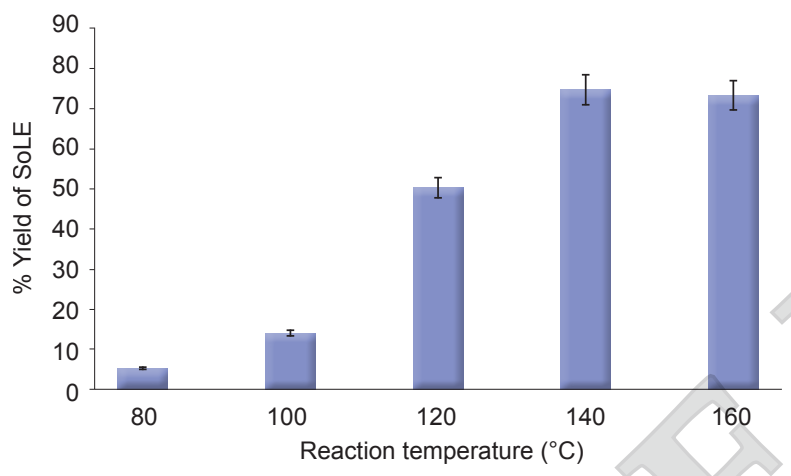

Figure 7. Effect of reaction temperature on the yield of SoLE.

\section{Characterisation of SoLE}

FTIR spectra. FTIR spectra of both solketal and ML were compared with the product in order to prove that the esterification reaction between solketal and ML had taken place. In the FTIR spectra (Figure 8), the absorption band at $3421 \mathrm{~cm}^{-1}$ assigned to $\mathrm{C}-\mathrm{OH}$ stretching of hydroxyl group of solketal had almost flattened, indicating reaction had happened at the -OH group and SoLE was produced.

${ }^{1} \mathrm{H}$ and ${ }^{13} \mathrm{C}$ NMR analysis. Figure 9 shows the ${ }^{1} \mathrm{H}-$ and ${ }^{13} \mathrm{C}$-NMR spectra of SoLE. The chemical shift at 1.32 and 1.4 ppm in ${ }^{1} \mathrm{H}-\mathrm{NMR}$ spectrum (Figure 9a) correspond to two prominent methyl groups $\left(-\mathrm{CH}_{3}\right)$ in solketal. The protons attached adjacent to ketonecarbonyl and ester-carbonyl in ML were featured at $2.16(\mathrm{H}), 2.58(\mathrm{G})$ and $2.73(\mathrm{~F})$ ppm, respectively. Peaks between 3.7 (C) and 4.3 (D) ppm were related to the protons of $-\mathrm{CH}_{2}-$ and $-\mathrm{CH}-$ central carbon in the glyceride unit correspondingly. Lost of $\mathrm{CH}_{2}-\mathrm{OH}$ protons peak in this region marked the occurance of transesterification reaction between $\mathrm{ML}$ and solketal. For the ${ }^{13} \mathrm{C}-\mathrm{NMR}$ spectrum (Figure $9 b$ ), the prominent paired methyl group in solketal (B and A) appeared at 25.4 and 26.7 ppm, respectively. The glyceride carbons present in $-\mathrm{CH}_{2}-$ groups (C) and central carbon (D) can be observed at 64.9 to $73.6 \mathrm{ppm}$, correspondingly. In addition, peaks at $27.8 \mathrm{ppm}$ and $37.9 \mathrm{ppm}(\mathrm{F})$ correspond to the $-\mathrm{CH}_{2}-$ group adjacent to ester and ketone group, respectively. While peak at $29.9 \mathrm{ppm}(\mathrm{H})$ relates to $-\mathrm{CH}_{3}$ group of ML.

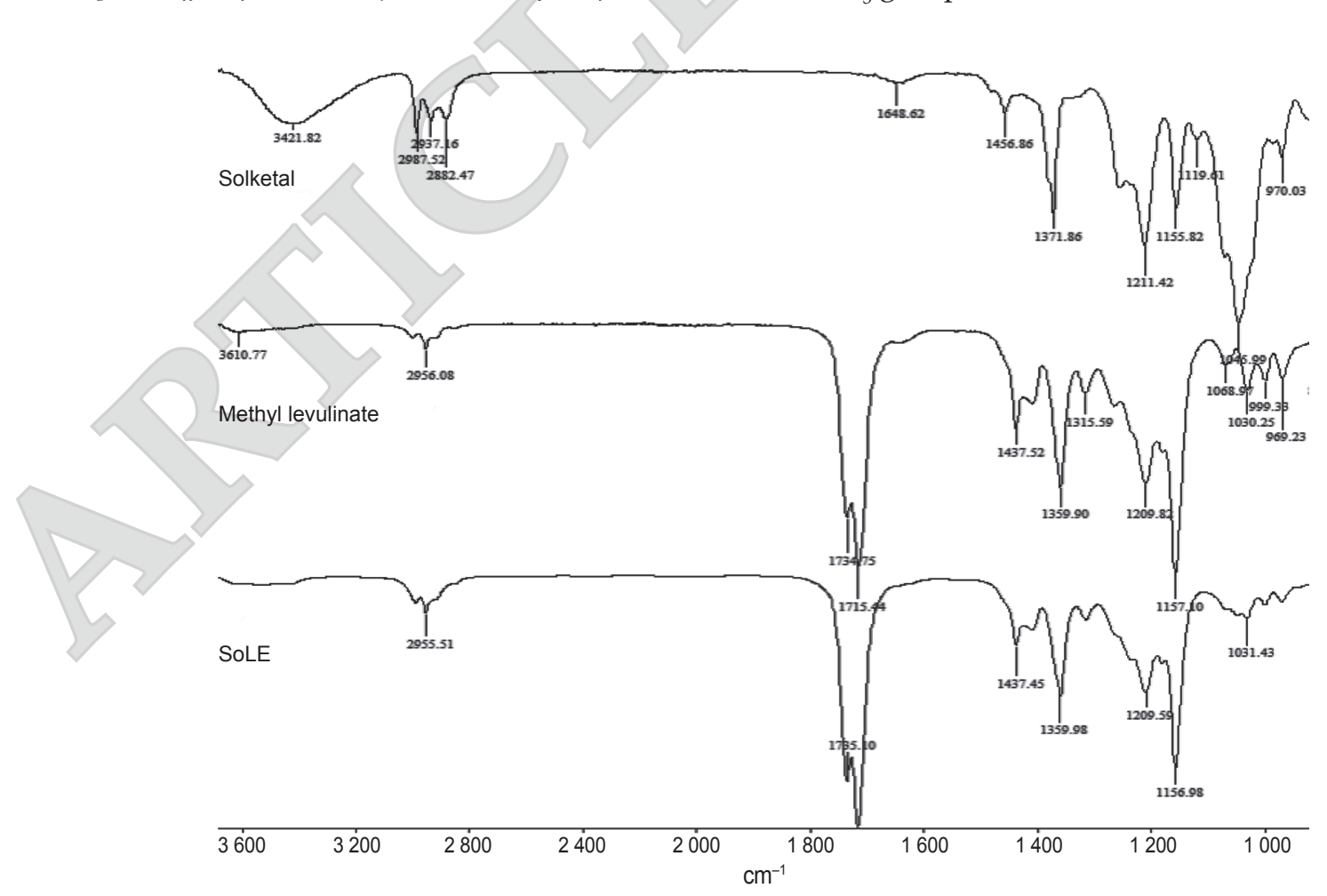

Figure 8. Fourier transform infrared (FTIR) spectrum of SoLE obtained from $\mathrm{Na}_{2} \mathrm{CO}_{3}$-catalysed transesterification between solketal and methyl levulinate $(M L)$ at 1:3 molar ratios and at $140^{\circ} \mathrm{C}$ for $4 \mathrm{hr}$. 
(a)

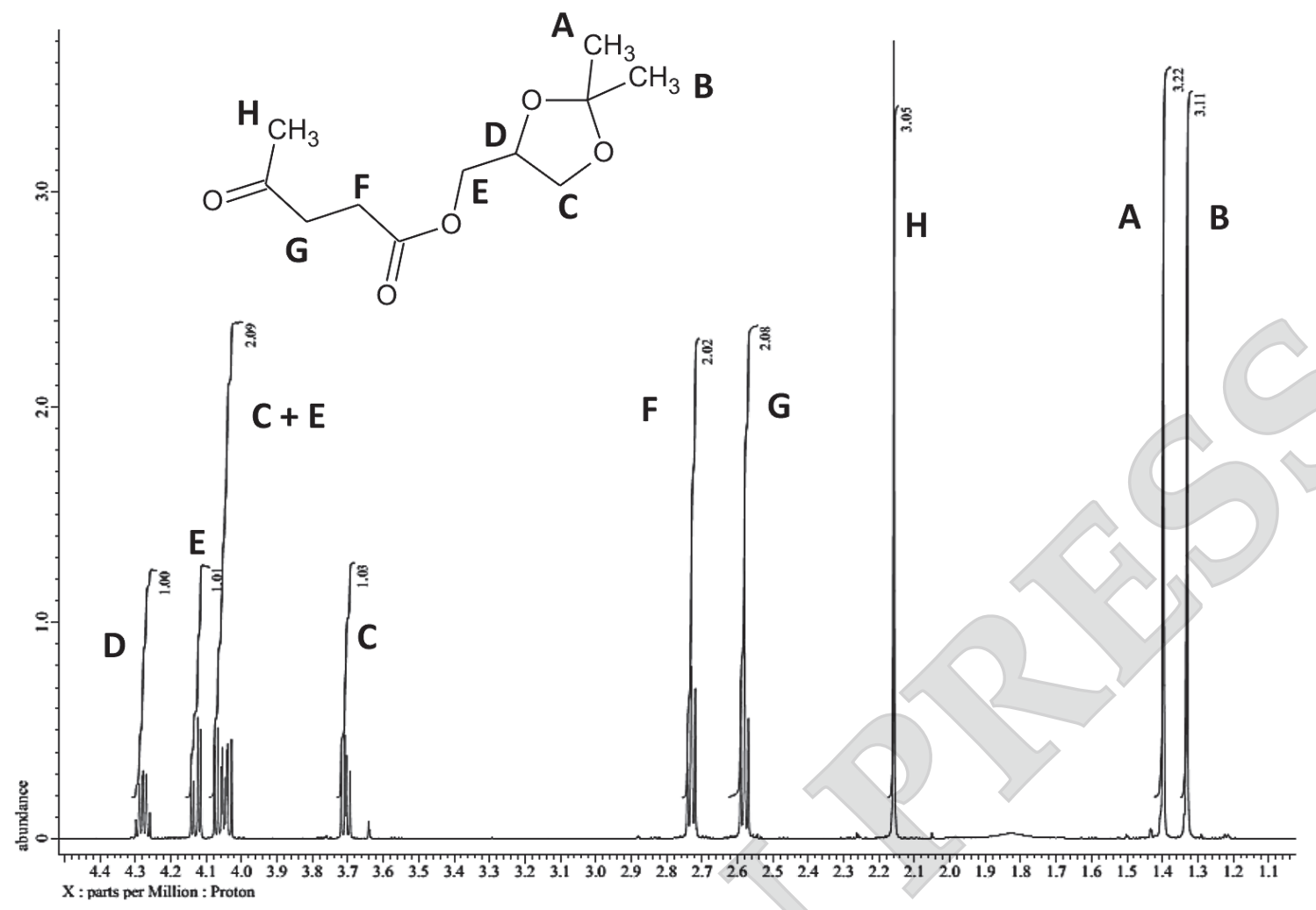

(b)

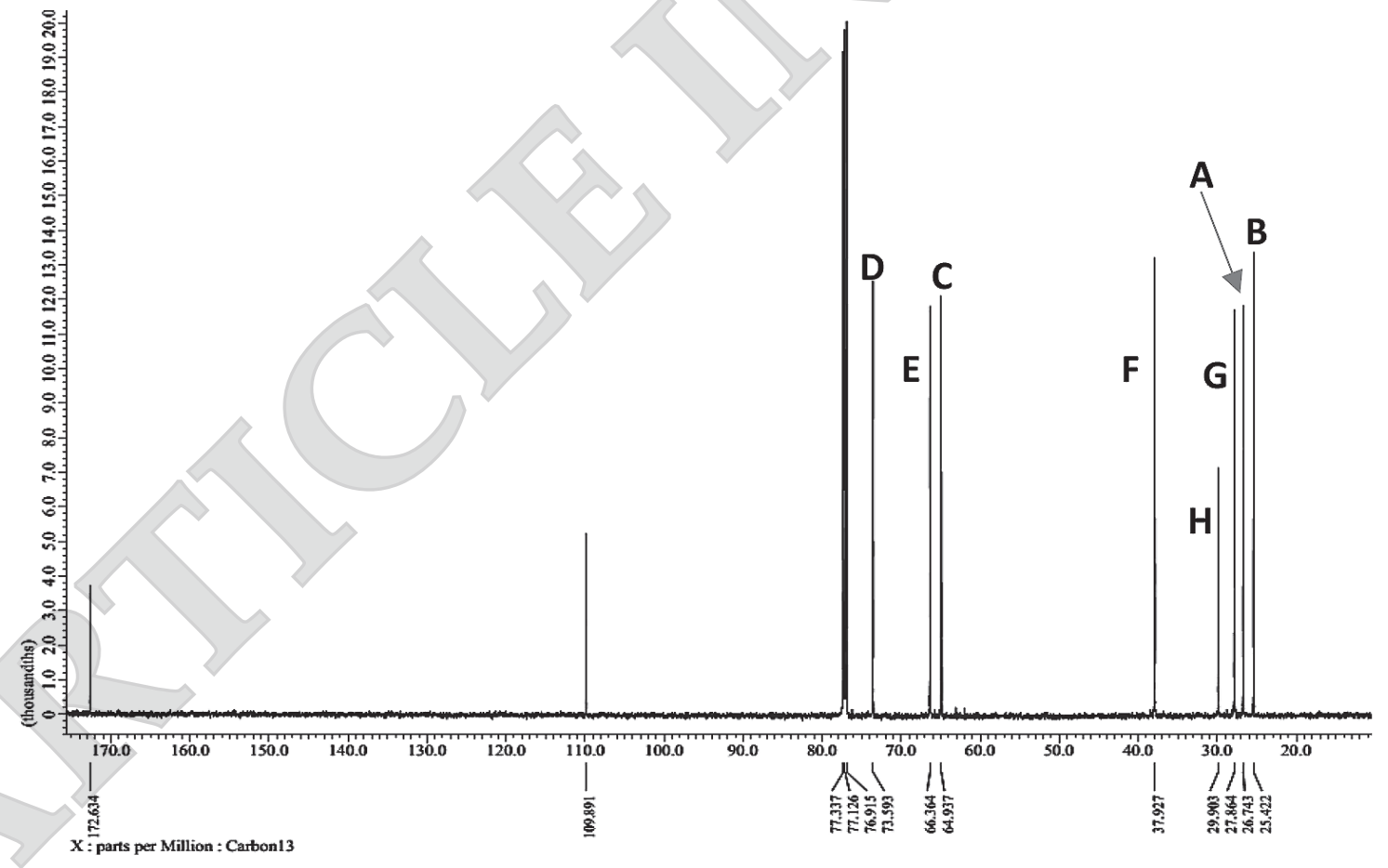

Figure 9. (a) The ${ }^{1} \mathrm{H}-\mathrm{NMR}$ and (b) ${ }^{13} \mathrm{C}-\mathrm{NMR}$ spectrum of SoLE obtained from $\mathrm{Na}_{2} \mathrm{CO}_{3}$-catalysed transesterification between solketal and $M L$ at 1:3 mole ratio, $140^{\circ} \mathrm{C}$ for $4 \mathrm{hr}$.

GC analysis of SoLE. The formation of SoLE was confirmed qualitatively via GC analysis. The GC chromatogram of the product confirmed that the synthesised product contains high percent composition of SoLE $(95 \%)$ as represented by a peak at retention time at 11.79 min (Figure 10). The chromatogram also indicated the existence of two other minor products with low percent composition namely methly levulinate and solketal, which appeared at $4.63 \mathrm{~min}$ and $5.83 \mathrm{~min}$, respectively. 


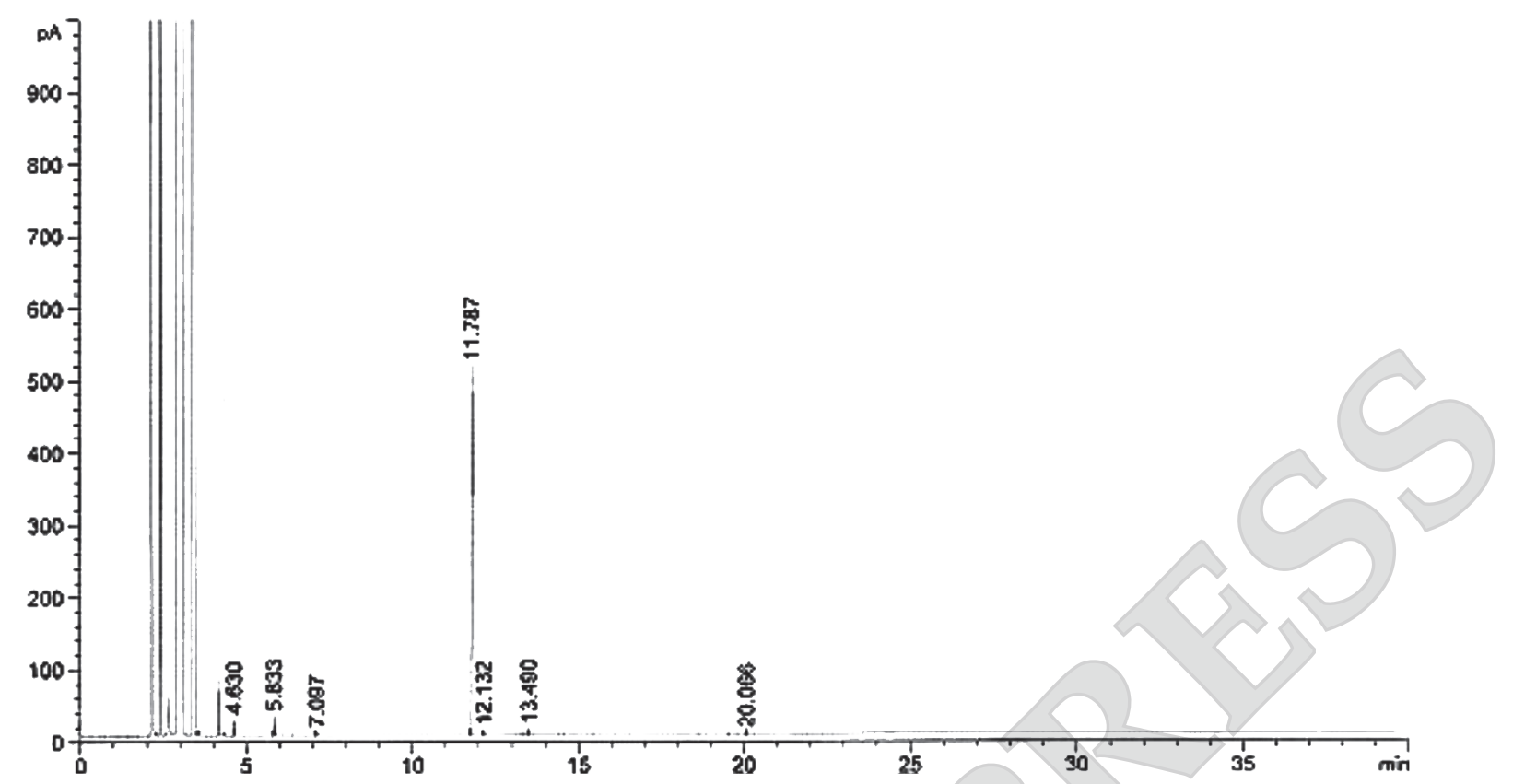

Figure 10. Gas chromatography (GC) chromatogram of solketal levulinate ester (SoLE) obtained from sodium carbonate $\left(\mathrm{Na}_{2} \mathrm{CO}_{3}\right.$ )-catalysed esterification between solketal (Sol) and methyl levulinate $(M L)$ at 1:3 mole ratios and at $140^{\circ} \mathrm{C}$ for $4 \mathrm{hr}$.

\section{Potential Uses of SoLE}

Solketal esters has interesting properties that are between those of cyclic acetal and glycerol ester. While current uses of solketal ester are still limited, solketal ester is proposed as a promising bio-based alternative in both direct and indirect applications.

Solketal has been reported to be applied as a fuel improver. Solketal was showed to decrease the particulate emission and enhanced the cold flow properties of liquid transportation fuels (Pariente et al., 2009). It helps to reduce the gum formation, improves the oxidation stability, and enhances the octane number when added to gasoline (Mota et al., 2010). Maksimov et al. (2011) described its use as a multipurpose solvent and a plasticiser in the polymer industry and a solubilising and suspending agent in pharmaceutical preparations.

Solketal and their cyclic group members has been reported as a useful fuel additive for enhancing octane number of gasoline. It was reported to reduce the gum formation and increased the octane number of gasolin (Lozano et al., 2016; Mota et al., 2010; Nanda et al., 2016). Lozano et al. (2016) has reported on producing oxygenated biofuels, based on FAME and fatty acid solketal ester mixtures, by lipase-catalysed transesterification of several vegetable oils or direct esterification of free fatty acid with methanol or solketal in ionic liquid. Other than that biodiesels formulations based on mixtures of FAME and FAGE have been described as very efficient for diesel engines. Biodiesel blends up to $20 \%$ volume fraction (vol. \%) of FAGE, exhibitied an excellent suitability as liquid fuel (e.g. viscosity, cetane number, adiabatic flame temperature, etc.), as it was demonstrated by testing in an automotive engine (Lapuerta et al., 2015; Lozano et al., 2016; Nanda et al., 2016; Perosa et al., 2016).

Since solketal ester has attracted considerable attention in the fuel and biodiesel sector. We have evaluated the fuel properties of biodiesel blend with SoLE. The density of the mixture increased upon addition of SoLE. The blended biodiesel became slightly viscous with increasing SoLE amounts. The acid number of biodiesel increased upon blending with SoLE. The pour point of biodiesel was lowered to $14^{\circ} \mathrm{C}$ by the addition of 20 vol. \% SoLE. The blending with SoLE had improved the cold flow performance of the biodiesel. The cloud point of biodiesel was also improved with the addition of 20 vol. \% SoLE. This work will assist in further evaluation of SoLE as cold flow improver of biodiesel fuel.

On the other hand, solketal ester also has been reported to show potential as antimicrobial agent by Mendoza-Ortiz et al. (2020). In their study, they reported that solketal palmitate had showed antifungal activity against Candida albicans and Candida parapsilosis, with minimum inhibitory concentration (MIC) between 200 and $400 \mu \mathrm{g} \mathrm{mL}^{-1}$.

\section{CONCLUSION}

In this study, SoLE was successfully synthesised in the presence of basic catalyst, $\mathrm{Na}_{2} \mathrm{CO}_{3}(1.5 \%)$. Optimum reaction temperature and reaction time to obtain high yield of SoLE were $140^{\circ} \mathrm{C}$ for $4 \mathrm{hr}$ reaction. The best molar ratio to obtain high yield of SoLE was 1:3 of ML:solketal. Analysis by GC, FTIR 
and NMR confirmed the structure and composition of SoLE. The highest yield of SoLE obtained using the optimised parameters was $75 \%$ with the purity of $95 \%$. The optimised reaction procedure to synthesise SoLE may give opportunity to industrial players in specialty chemical for production at larger scale. As described in potential application of SoLE, this research prospective will increase the uses of glycerol and chemical derived from biomass, which can boost the momentum of green chemical usage in fuel industry.

\section{ACKNOWLEDGEMENT}

The authors wish to thank the Director-General of MPOB for permission to publish this article and for the funding of this research project.

\section{REFERENCES}

Adeleye, A T; Louis, H; Akakuru, O U; Joseph, I; Enudi, O C and Michael, D P (2019). A review on the conversion of levulinic acid and its esters to various useful chemicals. AIMS Energy, 7(2): 165-185. DOI: 10.3934/ energy.2019.2.165.

Anitha, M; Kamarudin, S K and Kofli, N T (2016). The potential of glycerol as a value-added commodity. Chem. Eng. J., 295: 119-130. DOI: 10.1016/J. CEJ.2016.03.012.

Atadashi, I M; Aroua, M K; Sulaiman, N M N and Abdul Aziz, A R (2013). The effects of catalysts in biodiesel production - A review. J. Ind. Eng. Chem., 19(1): 14-26. DOI: 10.1016/j.jiec.2012.07.009.

Bart, H J; Reidetschlager, J; Schatka, K and Lehmann, A (1994). Kinetics of esterification of levulinic acid with $n$-butanol by homogeneous catalysis. Ind. Eng. Chem. Res., 33: 21-25.

Bozell, J J; Moens, L; Elliott, D C; Wang, Y; Neuenscwander, G G; Fitzpatrick, S W; Bilski, R J and Jarnefeld, J L (2000). Production of levulinic acid and use as a platform chemical for derived products. Resour. Conserv. Recycl., 28: 227-239.

Castro, G AD and Fernandes, S A (2021). Microwaveassisted green synthesis of levulinate esters as biofuel precursors using calix[4]arene as an organocatalyst under solvent-free conditions. Sustain. Energ. Fuels, 5: 108-111. DOI: 10.1039/D0SE01257B.

Deutsch, J; Martin, A and Lieske, H (2007). Investigations on heterogeneously catalysed condensations of glycerol to cyclic acetals. J. Catal., 245(2): 428-435. DOI: 10.1016/j.jcat.2006.11.006.
Din, N S M N M; Kian, Y S; Soi, HS; Zan, A M; Adnan, $S$ and Yusop, R M (2019). Synthesis of glycerol trilevulinate ester: Effect of reaction parameters. J. Oil Palm Res., 31: 624-633.

Fukuda, H; Kondo, A and Noda, H (2001). Biodiesel fuel production by transesterification of oils. J. Biosci. Bioeng., 92(5): 405-416. DOI: 10.1016/S13891723(01)80288-7.

Girisuta, B and Heeres, H J (2017). Levulinic acid from biomass: Synthesis and applications. Production of Platform Chemicals from Sustainable Resources. Biofuels and Biorefineries (Fang, Z; Smith, Jr. R and Qi X eds.). Springer, Singapore. p. 143-169.

Ilgen, O; Yerlikaya, S and Akyurek, F (2017). Synthesis of solketal from glycerol and acetone over amberlyst-46 to produce an oxygenated fuel additive. Period. Polytech. Chem. Eng., 61(2): 144-148. DOI: $10.3311 /$ PPch.8895.

Joshi, H; Moser, B; Toler, J; Smith, W and Walker, $\mathrm{T}$ (2011). Ethyl levulinate: A potential bio-based diluent for biodiesel which improves cold flow properties. Biomass Bioenerg., 35(7): 3262-3266. DOI: 0.1016/j.biombioe.2011.04.020.

Karinen, R S and Krause, A O I (2006). New biocomponents from glycerol. Appl. Catal. A Gen., 306: 128-133. DOI: 10.1016/j.apcata.2006.03.047.

Kumar, P; Kumar, S; Shah, S and Kumar, S (2021). Study of performance parameters and emissions of four stroke ci engine using solketal-biodiesel blends. SN Appl. Sci., 3(59). DOI: 10.1007/ s42452-020-04073-3.

Lapuerta, M; Rodríguez-Fernández, J; Estevez, C and Bayarri, N (2015). Properties of fatty acid glycerol formal ester (FAGE) for use as a component in blends for diesel engines. Biomass Bioenerg., 76: 130-140. DOI: 10.1016/j.biombioe.2015.03.008.

Li, L; Korányi, T I; Sels, B F and Pescarmona, P P (2012). Highly-efficient conversion of glycerol to solketal over heterogeneous Lewis acid catalysts. Green Chem., 14: 1611-1619.

Liang, X; Fu, Y and Chang, J (2020). Sustainable production of methyl levulinate from biomass in ionic liquid-methanol system with biomassbased catalyst. Fuel, 259: 116246. DOI: 10.1016/j. fuel.2019.116246.

Liu, Y; Lotero, E and Goodwin Jr., J G (2006). A comparison of the esterification of acetic acid with methanol using heterogeneous versus homogeneous acid catalysis. J. Catal., 242(2): 278-286. DOI: 10.1016/j.jcat.2006.05.026. 
Lozano, P; Gomez, C; Nicolas, A; Polo, R; Nieto, S; Bernal, J M; García-Verdugo, E and Luis, S V (2016). Clean enzymatic preparation of oxygenated biofuels from vegetable and waste cooking oils by using spongelike ionic liquids technology. ACS Sustainable Chem. Eng., 4: 6125-6132. DOI: 10.1021/ acssuschemeng.6b01570.

Maksimov, A L; Nekhaev, A I; Ramazanov, D N; Arinicheva, Y A; Dzyubenko, A A and Khadzhiev, S N (2011). Preparation of high-octane oxygenate fuel components from plant-derived polyols. Pet. Chem., 51: 61-69.

Mendoza-Ortiz, P A; Gama, R S; Gómez, O C; Luiz, J H H; Fernandez-Lafuente, R; Cren, E C and Mendes, A A (2020). Sustainable enzymatic synthesis of a solketal ester - Process optimization and evaluation of its antimicrobial activity. Catalysts, 10(2): 218. DOI: 10.3390/ catal10020218.

Mota, C J A; da Silva, C X A; Rosenbach, N; Costa, J and da Silva, F (2010). Glycerin derivatives as fuel additives: The addition of glycerol/acetone ketal (solketal) in gasolines. Energy Fuels, 24: 2733-2736. DOI: 10.1021 / ef9015735.

Nanda, M R; Zhang, Y; Yuan, Z; Qin, W; Ghaziaskar, H S and Xu, C (2016). Catalytic conversion of glycerol for sustainable production of solketal as a fuel additive: A review. Renew. Sust. Energ. Rev., 56: 1022-1031. DOI: 10.1016/j.rser.2015.12.008.

Oliveira, B L and da Silva, V T (2014). Sulfonated carbon nanotubes as catalysts for the conversion of levulinic acid into ethyl levulinate. Catalysis Today, 234: 257-263. DOI: 10.1016/j.cattod.2013.11.028.

Pariente, S; Tanchoux, N and Fajula, F (2009). Etherification of glycerol with ethanol over solid acid catalysts. Green Chem., 11: 1256-1261. DOI: 10.1039/B905405G.

Parveez, G K A; Hishamuddin, E; Loh, S K; Ong-Abdullah, M; Salleh, K M; Bidin, M N I Z; Sundram, S; Hasan, Z A A and Idris, Z (2020). Oil palm economic performance in Malaysia and R\&D progress in 2019. J. Oil Palm Res., 32(2): 159-190. DOI: 10.21894/jopr.2020.0032.

Perosa, A; Moraschini, A; Selva, M and Noè, M (2016). Synthesis of the fatty esters of solketal and glycerol-formal: Biobased specialty chemicals. Molecules, 21: 170-178. DOI: 10.3390/ molecules21020170.

Pileidis, F D; Tabassum, M; Coutts, S and Titirici, M-M (2014). Esterification of levulinic acid into ethyl levulinate catalysed by sulfonated hydrothermal carbons. Chinese J. Catalysis, 35: 929-936. DOI: 10.1016/S1872-2067(14)60125-X.

Rackemann, D W and Doherty, W O (2011). The conversion of lignocellulosics to levulinic acid. Biofuels, Bioprod. Bioref., 5(2): 198-214. DOI: 10.1002 / bbb.267.

Ramadhas, A S; Jayaraj, S and Muraleedharan, C (2005). Characterization and effect of using rubber seed oil as fuel in the compression ignition engines. Renew. Energy, 30: 795-803. DOI: 10.1016/j. renene.2004.07.002.

Rastegari, H and Ghaziaskar, H S (2015). From glycerol as the by-product of biodiesel production to value-added monoacetin by continuous and selective esterification in acetic acid. J. Ind. Eng. Chem., 21: 856-861. DOI: 10.1016/j.jiec.2014.04.023.

Sankaranarayanan, S; Jindapon, W and Ngamcharussrivichai, C (2017). Valorization of biodiesel plant-derived products via preparation of solketal fatty esters over calcium-rich natural materials derived oxides. J. Taiwan Inst. Chem. Eng., 81: 57-64. DOI: 10.1016/j.jtice.2017.10.007.

Song, D; An, S; Lu, B; Guo, Y and Leng, J (2015). Arylsulfonic acid functionalized hollow mesoporous carbon spheres for efficient conversion of levulinic acid or furfuryl alcohol to ethyl levulinate. Appl. Catal. B: Environ., 179: 445-457. DOI: $10.1016 /$ j.apcatb.2015.05.047.

Suriyaprapadilok, N and Kitiyanan, B (2011). Synthesis of solketal from glycerol and its reaction with benzyl alcohol. Energy Procedia, 9: 63-69. DOI: 10.1016/j.egypro.2011.09.008.

Tiong, Y W; Yap, C L; Gan, S and Yap, W S P (2019). Optimisation studies on the conversion of oil palm biomass to levulinic acid and ethyl levulinate via indium trichloride-ionic liquids: A response surface methodology approach. Ind. Crops Prod., 128: 221-234.

Torres, M; Jiménez-Osés, G; Mayoral, J A; Pires, E and de Los Santos, M (2012). Glycerol ketals: Synthesis and profits in biodiesel blends. Fuel, 94: 614-616. DOI: 10.1016/j.fuel.2011.11.062.

Trifoi, A R; Agachi, P Ş and Pap, T (2016). Glycerol acetals and ketals as possible diesel additives. A review of their synthesis protocols. Renew. Sust. Energ. Rev., 62: 804-814.

Unlu, D; Boz, N; Ilgen, O and Hilmioglu, N (2018). Improvement of fuel properties of biodiesel with 
bioadditive ethyl levulinate. Open Chem., 16: 647652. DOI: $10.1515 /$ chem-2018-0070.

Vázquez-Castillo, J A; Contreras-Zarazúa, G; Segovia-Hernández, J G and Kiss, A A (2019). Optimally designed reactive distillation processes for eco-efficient production of ethyl levulinate. J. Chem. Technol. Biotechnol., 94: 2131-2140. DOI: $10.1002 /$ jctb. 6033 .

Xu, Y; Guo, P; Chang, C; Li, P; Zhao, S and Xu, G (2020). Aluminum chloride-catalyzed conversion of levulinic acid to methyl levulinate: Optimization and kinetics. J. Chem. Technol. Biotechnol., 95(8): 22512260. DOI: 10.1002 / jctb.6413.

Pouilloux, Y; Me'tayer, S and Barrault, J (2000). Synthesis of glycerol monooctadecanoate from octadecanoic acid and glycerol. Influence of solvent on the catalytic properties of basic oxides. C. R. Acad. Sci. - Series IIC - Chem., 3: 589-594.

Yu, C-C; Lee, Y-S; Cheon, B-S and Lee, S-H (2003). Synthesis of glycerol monostearate with high purity. Bull. Korean Chem. Soc., 24(8): 1229-1231. 